\title{
A RELAÇÃO COM AS NORMAS NA AMÉRICA LATINA E O ORDINÁRIO TRABALHO MORAL DO SUJEITO*
}

THE RELATIONSHIP WITH NORMS IN LATIN AMERICA

AND THE ORDINARY MORAL WORK OF THE SUBJECT

RESUMO: A pesquisa aponta a necessidade de desenvolvimento da sociologia jurídica da norma, em especial, para lidar com a relação que se tem com as normas, em países da América Latina. Iniciando com uma exposição referente a como os clássicos lidam com essa relação, o texto se desenvolve com a literatura mais recente, apresenta dados empíricos sobre o caso Chile, quando identifica quatro configurações de sujeito em relação com as normas. A pesquisa conclui pela importância e necessidade de avançar nessa linha de análise teórica e empírica para compreender e explicar o trabalho moral ordinário do sujeito.

Palavras-chave: Normatividade. Sociologia jurídica. Cultural jurídica. América Latina.
ABSTRACT: The research points out the need to develop the juridical sociology of the norm, in particular, to deal with the relationship with standards in Latin American countries. Beginning with an exposition about how the classics deal with this relationship, the text develops with the most recent literature, presents empirical data on the Chile case, when it identifies four configurations of subject in relation to norms. The research concludes by the importance and necessity of advancing in this line of theoretical and empirical analysis to understand and explain the ordinary moral work of the subject.

Keywords: Normativity. Sociology of law. Legal culture. Latin America.

* Tradução de Artur Stamford da Silva. Artigo publicado originalmente em: KRON, Stefanie; COSTA, Sérgio; BRAIG, Marianne. Democracia y reconfiguraciones contemporáneas del derecho en América Latina. Frankfurt/Madrid: Vervuert, 2012. Agradeço a Editora Vervuert pela autorização para publicar na RBSD, porém apenas em português.

\footnotetext{
${ }^{1}$ Profesora titular Universidad de Chile.
} 


\section{INTRODUÇÃO}

As ciências sociais têm interesse desde seu nascimento pelo tema das normas. Isso se dá, certamente, porque sua consolidação como disciplina esteve inextricavelmente ligada à inquietude moral e política que recorre às sociedades europeias no começo do século XIX (NISBET, 1973).

Como é possível reconhecer, ainda quando não de maneira exclusiva, o mainstream da disciplina focou muito nesse problema, pondo o acento em diferentes assuntos: a função das normas para a integração (Durkheim), a questão da legitimidade das regras (Weber, Habermas); o processo de interiorização normativa (Parsons, Mead); o problema do desvio e das sanções (formais e informais) presentes em todo grupo (Merton, Goffman); a articulação entre o dever moral consciente e as rotinas incorporadas (Bourdieu, Giddens); sem esquecer, claro, a incessante produção de novas normas e valores (Joas, Touraine). Também se constituiu em um ponto de corte entre autores o peso dissimilar outorgado à função que cumprem as normas: a) a de integração social: ou seja, a função de definir critérios e obrigações pelas quais os indivíduos são vinculados a um grupo, b) a de orientação: enquanto definem o permitido, o proibido e nessa medida reduzem a complexidade da eleição de metas e meios; ou c) a função de coordenação: ao permitir a estabilização contra fática das expectativas de ação bem como com o assegurar a coordenação dos intercâmbios entre indivíduos e subsistemas a longo prazo (THOME, 2003).

A presença deste debate clássico nas ciências sociais na América Latina foi, no entanto, relativa, porque o ponto de partida foi diferente. Não é que se desconhecia a importância da relação com as normas, como mostram as análises culturais clássicas. Pelo contrário, as normas e a relação dos latino americanos com as normas foi preocupação de base constante nas discussões sobre nossas sociedades. Não obstante, o que caracteriza esta discussão é que na abordagem desta temática, mais que de uma pregunta, se partiu de uma certeza: nossa histórica conflitiva relação com a lei. Dessa maneira, se tomou como premissa que nossa relação com a lei se caracterizava por uma dinâmica particular: uma 
submissão retórica à lei que não implicava necessariamente um impacto para nossas condutas. Ao definir esta relação com a lei como traço distintivo, ela serviu para dar conta da cultura, idiossincrática e de funcionamento de nossas sociedades. Ao mesmo tempo, e por outro lado, como discutiremos em detalhe mais a diante, serviu de base e de fonte para os argumentos a partir dos quais durante muito tempo a América Latina, em relação ao tema das normas, foi caracterizada por suas deficiências. O ponto de partida adotado nessas leituras foi obstaculizado por uma concepção mais rica e complexa de nossas sociedades e, na mesma medida, foi abonada a retórica do déficit que governou as leituras da região (ARAUJO, 2009a; MARTUCCELLI, 2010).

Se na discussão europeia e estadounidense se colocou acento no problema de como se explica que os indivíduos sejam vinculados ao grupo, e se partiu da evidência da integração para daí se discutir as possibilidades de desvios (Merton), as ameaças à mesma (Durkheim e o conceito de anomia) ou, prova confiável do peso da integração, de seus efeitos patógenos (no modo da dominação ou da sujeição como no caso de Bourdieu e Foucault), na América Latina o dato de base foi precisamente o desvio, a anomia e a desregulação. O que constituía caso de exceção em outras regiões, era considerado a média ao se pensar as sociedades latino americanas. E elas foram pensadas, na maior parte dos casos, em modo de déficit e de ameaça, de condenação moral.

As reflexões que apresentarei neste artigo, ao partir do diagnóstico apresentado, se nutrem da conviç̧ão que requeremos na América Latina de um esforço para ampliar os debates e os estudos empíricos no âmbito da sociologia das normas, assim como por modificar a perspectiva analítica que temos utilizado para abordar este problema.

Devemos ampliar estes estudos e pesquisas porque a região conheceu os processos políticos decisivos e contraditórios nas últimas décadas, os quais obrigam às sociedades civis latino americanas a revisitar e repensar de maneira profunda suas relaciones com as normas. Seja porque as experiências de violência política das últimas décadas impunham uma tomada de consciência coletiva sobre a centralidade do direito e dos ideais na produção de uma vida civilizada (como no caso do Chile ou da Argentina, por exemplo). Ou seja, pelo surgimento de fenômenos inéditos de corrução, de informalidade, a presença permanente de atividades ilegais na vida política e social (tráfico de drogas etc..) e, em 
muitas cidades do continente, de inquietantes fenômenos de violência. Em qualquer caso, a democracia bem como a justiça aparecem diante de nós brutalmente, como intimamente dependentes do funcionamento das regras. A relação com as normas exige ser reconhecida como um item central para a construção de sociedades democráticas. Resulta evidente que o êxito dos esforços de democratização das sociedades não será resultado exclusivamente do desenvolvimento destes processos na chave política, isso depende também, seguindo uma intuição de O’Donnell, do grau de "democraticidade" das relações sociais (O’DONNELL, 1984, p. 21).

Porém, se a importância de se ampliar os estudos sobre as relações com as normas é reforçada pelos processos socio-históricos, não é esta ampliação a única tarefa pendente, como já mencionado. Um argumento central aqui é que se requer uma sociologia das normas que ponha em questão a certeza transgressora e deficitária da qual se pode partir para converter a relação dos indivíduos com as normas numa autêntica pergunta de pesquisa. Ou seja, que necessitamos de uma sociologia das normas que exija a produção de um marco no qual a compreensão prime sobre a condenação moral.

Neste artigo me proponho, em primeiro lugar, a tecer uma análise das maneiras com que a premissa do carácter transgressor da relação com as normas dos latino americanos atua nas produções contemporâneas sobre o tema, bem como sobre as consequências que têm uma certa impregnação em nossas análises. Em segundo lugar, atrelado ao anterior, apresentarei uma proposta de abordagem conceitual para o estudo da relação com as normas que põem acento no rendimento moral ordinário dos indivíduos em sua relação com esta. Finalmente, apresentarei este modelo em construção quanto ao caso do Chile, me baseando em resultados de pesquisa empírica.

\section{OS ESTUDOS SOBRE AS NORMAS NA AMÉRICA LATINA}

\subsection{Contexto e antecedentes}

Os trabalhadores que começaram a abordar o problema dos padrões como um problema factual tenderam a se desenvolver muitas vezes independentemente uns dos outros. 
Um grupo de estudos tem se concentrado nos últimos anos em apresentar, muitas vezes por meio de pesquisas empíricas, as cartografias precisas dos atores envolvidos nos processos de transgressão, nos mecanismos de corrupção ou na consolidação da relação com a justiça (SMULOVITZ; URRIBARRI, 2007; SCHWARTZMAN, 2007). Outros, como certos trabalhos dedicados ao estudo do setor informal, estavam interessados principalmente em desvendar as relações estruturais desses fenômenos, pondo em evidência, inclusive de maneira polêmica, não tanto as relações de índole propriamente econômica, mas também os fatores que, desde a prática burocratizada das regras, sustentam esta atividade na região (DE SOTO, 1986). Feita a partir de uma gama de temáticas certamente mais extensas e complexas, e de uma base empírica que no passado recente, esses estudos sublinham sobre tudo os efeitos perversos ou a (in)eficácia do direito na América Latina (MENDEZ; O'DONNELL; PINHEIRO, 2002).

Não obstante, é provavelmente e já clássico e pioneiro o trabalho de Roberto Da Matta (1978), o qual abre caminhos de maneira mais clara aos estudos propriamente das relações dos indivíduos com as normas nas diferentes sociedades nacionais. Tanto o livro de Da Matta como o conhecido diálogo que se estabelecem com ele e, alguns anos mais tarde, com o texto de Guillermo O`Donnell (1984), ganha espaço o debate entre os interessados em pesquisar as formas específicas com que as regras de sociabilidade se operam em diferentes contextos nacionais. Nestes dois casos, a relação com as normas é discutida no âmbito do exercício da autoridade e das formas em que as relações hierárquicas são estruturadas em sociedades específicas. O livro de Da Matta, uma das referências mais importantes neste campo, oferece uma análise da sociedade brasileira baseada em diferentes ritos e formas de sociabilidade. O autor discute, por um lado, os ritos integrantes no Brasil, dentre os quais as estratégias de expressão controlada da transgressão, de todos os setores, mas especialmente populares, expressas plasticamente no Carnaval. Por outro lado, ele destaca a maneira autoritária e diversa como se mantém a verdadeira separação e subversão de posições sociais, o que expressa na famosa fórmula "Você sabe com quem está falando?". Ou seja, formas de transgressão das normas que são apoiadas e legitimadas pelo lugar privilegiado ocupado nas relações de poder e hierarquia. 
O texto de O'Donnell, defendido como um ensaio pelo autor, já que não está baseado em estudos empíricos, é construído em diálogo com a análise de Da Matta. Comparada ao caso brasileiro, a sociedade argentina aparece com maior grau de interações sociais e interclasses "democráticas", o que se refletiria na impregnação do tutear (tuteo/voseo ${ }^{2}$ ), na atitude "Eu trabalho, não sou servo" e na fórmula que serve de contraponto àquela do caso brasileiro: "E a mim, a que merda isso me importa?". Não obstante, o autor tem o cuidado de afirmar que se trata de uma sociedade democrática ou não-hierárquica.

A fórmula argentina reforça as hierarquias na mesma medida em que as revela, e ao mesmo tempo põe em cena os modos transgressivos e violentos de seu enfrentamento nesta sociedade, bem distante da "cordialidade" brasileira. Todavia, o ensaio de O'Donnell consiste propriamente em vincular estas observações sobre a sociabilidade com a dimensão mais macro, a da política. Em contraposição a este traço da sociabilidade argentina em términos políticos, se trata, para o autor, de uma sociedade claramente não democrática. O corporativismo anárquico implicou numa cena política marcada pela imposição de interesses, numa competência na qual o mais audaz ganha (equivalente à imagem do tráfico em Buenos Aires, no qual o que "mete la trompa"3 ganha). Uma competência em que toda arma é válida e na qual, por tanto, as práticas transgressivas das normas (corrução, desobediência ou uso seletivo da legislação etc.) são a tônica. Num nível ou no outro, e apesar de um maior igualitarismo presente na sociabilidade argentina, também aqui no Chile a leitura enfatiza o destino transgressivo da relação com as normas, seja porque este se sustenta como um modo de defesa contra a violência hierárquica, seja

\footnotetext{
${ }^{2}$ Em espanhol há, para segunda pessoa do singular: TÚ e USTED. Usted denota menor confiança e maior distancia social ou maior autoridade de quem estamos nos dirigindo. O Tú implica normalmente mais confiança, mais aproximação social, mais amizade com quem estamos conversando. TUTEO é a ação de usar o tu. Para O'Donnel, nesse contexto, o tuteo é uma mostra de um trato generalizado ao outro mais horizontal e menos hierárquico. Algo próximo ao TU e VOCÊ, porém em português se perdeu muito a ideia de cordialidade no uso do Você, inclusive se aproxima mais do Tu que da terceira pessoa. A origem Vossa Mercê hoje não se aplica. A distância social ou a ideia de cordialidade é usado: O Senhor [nota do tradutor, sob consulta à autora].

3 "Meter la trompa", no exemplo que dá O'Donnel sobre o trânsito de automóveis em Buenos Aires, quer dizer que quem é capaz de meter a parte dianteira do carro no meio do trânsito, é quem ganha. Como quando alguém quer passar de uma fila de carro para outra. Se se consegue meter a parte dianteira do carro, ainda que não tenha entrado completamente na fila que quer, ganha porque os outros carros não podem evitar que ele entre na fila. Ou seja, assim se impõe e se ganha espaço (com uso da força) [nota do tradutor, sob consulta à autora].
} 
porque se presente como efeito de uma lógica de interesses desprovida de da ética do bem comum.

Mesmo quando uma condenação moral ainda estava implícita nessas posições, e o modelo transgressivo opera nessas abordagens, ambas têm o enorme valor de tentar entender as formas efetivas de relacionamento com as regras presentes no continente.

\subsection{As características do campo}

O campo das discussões sobre a relação dos indivíduos com as normas na América Latina tem sido caracterizado principalmente pelas seguintes características: 1) seu escasso sustento empírico, 2) compartilhamento de um diagnóstico descritivo comum que desvela um marco de compreensão compartilhado.

Primeiro. Não obstante a potência explicativa que se tem enfatizado nesta dimensão, paradoxalmente, os estudos empíricos que se tem empreendido são extremadamente escassos. O debate tem seguido principalmente através da produção ensaística, ou sobre leituras indiretas sustentadas por interpretações culturalistashistoricistas (cf., por exemplo, só para o caso do Chile, LARRAín, 2001; GARRETÓN, 2000; JOCELYN HOLT, 1999).

Não é possível dar uma explicação certeira das razões desta característica do debate, que inclusive não se restringe a nossa região, porém, é plausível considerar que, uma das rações é que a abordagem desta temática requer uma aproximação do problema da moral social, entendida para além da mera conjunção de atitudes ou opiniões (como, por exemplo, as aproximações de tipo quantitativo por meio de pesquisa de opinião), o que necessariamente obriga à produção de perspectivas teórico e metodológicas trans ou interdisciplinares. Uma outra ração, vinculada ao pouco interesse por temas ligados ao campo da moral nas ciências socais latino americanas, especialmente aquelas associadas com uma posição crítica nas últimas quatro décadas, pelo menos. De um lado, pela convicção de que existiam outros temas prioritários como o desenvolvimento, a pobreza ou a democratização. De outro, porque a moral apareceu considerada como uma temática própria do reduto de posições conservadoras. O problema da moral individual e social não conseguiu ter o brilho que Ihe permitisse chamar atenção dentre pesquisadores sociais. 
A segunda característica do campo será abordada brevemente porque já tratei dela anteriormente: a América Latina estaria caracterizada pelo carácter transgressor dos indivíduos. É o que leio do texto fundamental nesse campo como no libro Carnavais, Malandros e Herois, de Roberto Da Matta, tal como acabamos de tratar. Porém, também, e ao final das contas, sobre sociedades como a chilena, na qual também contém a afirmação do "legalismo" que a caracterizaria, porém se discute a existência de um permanente "doble discurso" (SHEPARD, 2000). Uma relação obliqua com uma lei nunca suficientemente eficiente nem legítima é o que encontramos como pedra de toque neste debate.

O que resulta relevante por em relevo aqui é que esta interpretação revela a permanência de um enfoque que põe acento na distância entre as normas e os indivíduos e suas condutas. Isto se expressa nos diagnósticos culturais, porém também em muitos trabalhos que põem o acento explicativo na distância entre práticas e discursos ou representações. O problema aqui é que uma vez que temos definido a distância com a norma, não sabemos exatamente ainda o que significa isso na economia social e individual. Não é possível determinar sem forçar, por exemplo, sem isso o que chamo transgressão na análise, é concebido como transgressor e tem um efeito de erosão ou não na sociedade. Em contraposição, as leituras da transgressão estão moduladas por um implícito juízo moral ou de valor.

\subsection{Chaves interpretativas e suas armadilhas}

A distância entre os indivíduos e a norma tem sido interpretada pelo menos em duas grandes chaves. Em primeiro lugar: o desajuste entre normas e condutas é considerado principalmente como uma ameaça contra as sociedades. Um exemplo paradigmático neste sentido é o trabalho de Carlos Santiago Nino, para o caso da Argentina (NINO, 2005). Nino pressupõe que o que caracteriza a esta sociedade é a presença do que ele denomina de "anomia boba", que se refere ao estado de inobservância de normas jurídicas, sociais ou morais que são tomadas como contraproducentes para a sociedade. As dificuldades desse desenvolvimento e bem-estar 
argentino estariam correlacionadas com esta característica constitutiva da relação com as normas nesse país.

Uma segunda maneira que a distância entre conduta individual e norma é interpretada é aquela que entende tal desajuste não só como resultado inevitável, mas também positivo. O exemplo dos trabalhos de Nugent $(1996,1998,2003)$ é expressivo neste sentido, porém também uma parte das discussões dos estudos feministas sobre as transformações de gênero e o valor posto em questão normativa. Para Nugent, no caso peruano, a transgressão deve ser vista como resultado de acomodação e resistências às relações de poder numa sociedade hierárquica e num contexto do impulso modernizadormodernizante. A inobservância das normas é uma resposta ativa e positiva dos subordinados na reacomodação necessária numa sociedade em que certos setores perdem rapidamente as bases materiais e simbólicas da legitimidade que havia sustentado seu poder. A transgressão no Peru contemporâneo, seria assim, uma modalidade de resistência à hierarquia, mas também de agência modernizante social.

Se bem, os estudos que se localizam tanto na primeira quanto na segunda chave de leitura aportam ao debate sobre as regras nossa região, o certo é que é possível perfilar duas grandes armadilhas potenciais que derivam de cada uma dessas chaves de leituras.

$\mathrm{Na}$ armadilha normativista, as análises se dedicam a definir a distância entre ideal e atuação do indivíduo. Dessa maneira, as perguntas subjacentes a esta abordagem lidam com as razões que explicam porque os indivíduos não atuam segundo os ideais que dizem ter. Formulada deste modo, a noção de déficit joga um papel central e uma certa perplexidade e impotência que acompanham as interpretações. Esta perplexidade e o que é percebido como um aparente muro para a análise é efeito em boa medida da suposição de base destas posições: a existência de uma relação imediata entre as regras e os indivíduos. Dito de outro modo, o que está em jogo é a convicção que existiria uma relação direta entre os ideais e as condutas. A concepção moral é formal e abstrata. O que leva à exclusão da atuação na experiência social. Obvio que isso é matéria prima para o trabalho moralista que, por consequência, é extraída desse campo de análise. Esta armadilha normativista conduz a que a "insuficiência" ou "inferioridade moral" de latino americanos e latino americanas resulte pressuposto a qualquer conclusão. 
A armadilha pragmatista, por sua parte, está vinculada à suposição que há uma preeminência das determinações sociais sobre o indivíduo. A condutas destes são concebidas como resultado do empurrão da estrutura econômica ou das relações sociais, seja como acatamento, seja como reação reflexo delas. A qual é subjacente é a concepção de que existiria uma articulação imediata entre a experiência social e o sujeito. A experiência social aparece aqui como um todo explicativo suficiente da relação com a norma que estabelecem os indivíduos e, em muitos casos, é fundamento da desculpa moral baseada na denúncia social. Assim, por exemplo, uma certa lógica argumentativa destas posições propõe que é porque a experiência social está armada a partir de abusos permanentes que o recurso ao ideal seria uma atitude impossível. O que se exclui ou não se considera adequadamente aqui é a função do ideal na orientação das condutas. Como efeito da exclusão do ideal é óbvia para toda configuração do sujeito moral positiva e ordinariamente nos indivíduos.

Como é visível, em ambas as armadilhas, o juízo moral texturiza a análise social. $\mathrm{O}$ juízo moral que recai sobre o indivíduo no caso da armadilha normativista. Ou que recai sobre a sociedade, no caso da pragmatista. Nos dois casos, uma elisão dupla se evidencia: do lado do primeiro, a elisão da experiência social; do lado do segundo, a elisão da função do ideal. Em ambos, e isso é um argumento central neste texto, o que se revela é a omissão do ativo e ordinário trabalho moral dos indivíduos.

Tanto as respostas que põem acento nos efeitos modeladores das normas, como aquelas que privilegiam uma perspectiva mais pragmática, transportam o pressuposto que os indivíduos atuam e se orientam sem mediação alguma de seu próprio trabalho e principalmente da moral.

\subsection{Pensar as saídas}

Feito um breve estado da arte, como enfrentar, então, o estudo das relações dos indivíduos com as normas? A nosso juízo há três direções centrais:

1a) Evitar uma estrutura analítica que se centre na distância dos indivíduos em relação à norma, o que conduz necessariamente ao diagnóstico comum da transgressão. Pelo contrário, trata-se de atender aos processos que impactam nos indivíduos e que 
produzem e sustentam suas formas de relação com as normas e as formas nas quais eles respondem a elas. A proposta aqui é por a atenção não na distância dos indivíduos com a norma, mas sim na lógica de sua relação com ela.

2a) Superar a omissão do trabalho dos indivíduos ao se produzir como sujeitos e sujeitos morais. Isso implica integrar à análise do fato de que a ação individual, por mais banal ou insignificante que seja, está orientada por uma modalidade de sujeito, um sujeito que funciona como orientação e legitimação da ação.

3a) Complexificar os marcos conceituais para evitar elisões que empobrecem e mecanizem as análises. Resulta indispensável, neste sentido, reconhecer conjuntamente a função combinada do Ideal e da experiência social.

Em breve, respeitar a especificidade da relação dos indivíduos com a norma implica a criação de uma abordagem teórica e conceitual que garanta a apreensão da pluralidade de lógicas, marcos e estratégias que compõem esta relação. Para dizer de maneira mais precisa possível: o estudo dos indivíduos em sua relação com a norma implica dar conta das lógicas e estratégias a partir das quais se orientam e conduzem no social (se cruzam um semáforo vermelho, se rechaça uma oferta de corrução, si mobilizam recursos de influência fora da lei eticétara). Dito de outra maneira, ainda, quando alguém passa na frente de dezenas de pessoas graças a suas influencias, ele não pode ser entendido como simples cegueira ou definido como cinismo. É indispensável dar um passo a mais na análise, pois é necessário responder de que maneira uma ação tal está integrada pelos indivíduos de uma sociedade, portanto, na compreensão de seus atos e de onde extraem sua legitimação (ou não). Noutras palavras, de que modo e a partir de que noções de si e do mundo foi possível ter se tornado corrente o ato de passar por encima dos direitos das outras pessoas numa série de atitudes ou trajetórias individuais? Responder quais as modalidades em que indivíduos se relacionam com as normas supõe integrar a dimensão moral dos atos ordinários ao horizonte dos indivíduos comuns.

Em nossa perspectiva, uma inteligência da ação social que responda a estes requisitos passará por introduzir em nosso horizonte analítico e de maneira simultânea aos ideais e às experiências sociais próprias a uma sociedade, porém, restituindo em toda sua magnitude, o devido lugar ao ordinário trabalho moral do sujeito. 


\section{O ORDINÁRIO TRABALHO MORAL: AS CONFIGURAÇÕES DE SUJEITO}

Os procederes individuais não podem ser entendidos como respondendo isoladamente a um ou outro, ao ideal ou à experiência, porém, tão pouco, como uma combinação mecânica de ambos os elementos. Para evitar uma explicação mecanicista, se requer incorporar um terceiro termo que dê conta da função e da precipitação da articulação de ambas as dimensões. Este terceiro termo é o sujeito.

São as configurações de sujeito, as quais são fontes de orientação e legitimação das ações individuais e, por tanto, estão no lugar de dar conta da inteligência dos modos de atuação no social. Porém, cabe questionar, como entender a configuração do sujeito? É a tensão entre experiências sociais e ideais, das quais vão participar na definição das opções e modalidades de configuração do sujeito possível numa sociedade. Vejamos um exemplo: os princípios meritocráticos. Se minha experiência, já seja produzida pela vivência diretamente ou pelo que me foi relatado, me diz que as relações pessoais, e as influências que disso derivam, têm um peso significativo nos processos de seleção de pessoas e contratação, ainda que o ideal de sujeito moderno cujo valor reside em seus méritos individuais possam estar funcionando como ideal mobilizador para mim, eu posso me ver inclinado a atuar em função do que à primeira vista me parece melhor. O saber decantado do social mostra que meu valor reside num emaranhado de relações familiares e de amizades às quais pertenço e que posso mobilizar. O sujeito que posso ser se define então neste interregno que é constituído pelos ideais que me orientam e o que minha experiência social me diz sobre as vias possíveis, aconselháveis e eficientes para me apresentar e conduzir no social. Por suposto, as possibilidades de configuração de sujeitos são plurais numa sociedade. Não há uma só maneira na qual esta configuração se defina. Voltaremos a este ponto adiante quando apresentarmos um caso empírico.

Agora, o sujeito não é um produto acabado e permanente. Ele é trabalho constante de sua configuração, reconhecível nos momentos de sua atualização. O sujeito é resultado de um trabalho permanentemente inacabado de conformação no marco das expectativas, restrições e possibilidades sociais. Assim, uma configuração de sujeito é um produto sempre inconcluído e é, simultaneamente, o trabalho mesmo de sua permanente criação (ARAUJO, 2009a). Um trabalho que se desenvolve no marco dos desafios que se 
apresentam de cara aos ideais que funcionam como orientação e do saber decantado das experiências sociais.

É a ação combinada das experiências sociais em seu encontro com os horizontes produzidos pelo Ideal, o que vai definir as possibilidades e modalidades de cada um ao se configurar como sujeito: o que define as vias abertas e vedadas, as estratégias apropriadas e inapropriadas para se apresentar e habitar o social. Por outro lado, esta dualidade explica, por um lado, o carácter provisório - porque sempre estou obrigado, pelas experiências sociais, a produzir e reproduzir o trabalho de minha configuração enquanto sujeito. Por outro lado, permite dar conta do "ar de família" conservado ao longo do tempo - na medida em que os ideais inscritos no Ideal do Eu individual procuram uma relativa estabilidade.

A noção de configuração de sujeito, permite assim incorporar a dimensão subjetiva, porém distante de uma concepção intimista ou afetiva (por exemplo, PNUD, 1998; LECHNER, 2002), ou como mero excesso fantasmático (ZIZEK, 1992, 2001). Ao mesmo tempo, habilita incorporar ao sujeito sem cair no modelo que faz dele uma figura produto de um emaranhado puramente discursivo (FOUCAULT, 1998, 1990). O sujeito é a actualização que se deduz de um trajeto ou de um curso de ação, cujas condições de possibilidade estão definidas pela ação complexa e combinada dos ideais e das experiências sociais. Neste marco interpretativo, é indispensável compreender de maneira precisa o papel do Ideal. O Ideal não é referência única, ainda que sua ação seja constante. Por outro lado, e de maneira central, o sujeito ideal não é o sujeito encarnado. Primeiro, porque os ideais sociais não atuam de maneira direta e mecânica influindo nos modos de proceder dos indivíduos (como se supôs no fundo o modelo clássico da socialização), mas sim que encontram seu caminho por um processo de inscrição individual via Ideal do Eu. Segundo, porque o sujeito não precede à experiência. O sujeito se produz em relação com a experiência e em certa medida como efeito dela. Supor que há um sujeito ideal diverso do da experiência social, do qual se espera que cumpra com o respeito à norma, é, por assim dizer, um excesso de idealismo na concepção de sujeito, o que nos conduz a becos sem saída quando tentamos dá conta dos fenômenos que enfrentamos. 
As configurações de sujeito não são meramente normativas, no sentido de que funcionam como orientação e suporte, não estão constituídas puramente por uma dimensão ideal. Uma visão que, como mostra o célebre trabalho de Robert Bellah e sua equipe, conduz a privilegiar um número reduzido de modelos de sujeito, fortemente normativos, que os indivíduos se limitariam a encarnar em proporções variáveis (BELLAH et al., 1985). Desta maneira, o indivíduo não está liberto da ação do ideal. Noutras palavras, não está em posição de ser indefeso, como que de atuação passiva ou que acata necessariamente a dimensão normativa. Os ideais, os modelos de sujeito e os dispositivos que buscam encarná-los materialmente não se apropriam totalmente das consciências e dos corpos, porque a experiência social funciona como barreira e como uma parada. Visto desde a perspectiva do laço social e da convivência social: os ideais numa sociedade são intrinsecamente instáveis e frágeis porque estarão sempre à mercê dos impactos e requerimentos que emergem da experiência social.

Esta articulação permanente dá conta da maleabilidade das configurações de sujeito, como vimos sustentando, porém também da impossibilidade de considerar a experiência social e a ideal normativa fora dos efeitos de sua interação capturada pelo trabalho de sua articulação.

Passemos agora a mostrar uma aplicação desta proposta ao caso da relação dos indivíduos com as normas na sociedade chilena.

\section{O CASO DOS GERENTES (SETORES MÉDIOS) NO CHILE}

A pesquisa desenvolvida sobre o caso do Chile partiu da pergunta pela maneira como direito, enquanto ideal normativo, participa ou não da regulação das relaciones cotidianas entre as pessoas e entre estas e as instituições. Se questionou que conjunto de elementos a partir dos quais as ações dos indivíduos resultavam inteligíveis, assim como quais eram as formas de justificação e legitimação para o tipo de relação com as normas que eles estabeleciam ${ }^{4}$.

\footnotetext{
${ }^{4}$ Con la orientación de esta pregunta se aplicó la técnica de Grupos de Conversación Dramatización a hombres y mujeres de generaciones y dos sectores socioeconómicos distintos. Esta investigación fue posible gracias al apoyo de OXFAM Gran Bretaña. Mi agradecimiento a Carolina Ibarra, Claudia Moreno, y María Elena Fuentes por su aporte en
} 
Na sequência, me deterei a dar um exemplo preciso da maneira como os avatares do Ideal, as características da experiência social, se articula, em determinadas configurações de sujeito. A explicação da relação dos indivíduos com as normas se nutre dos destinos da inscrição do Ideal, da reconstrução da paisagem e das lógicas sociais, a partir das experiências dos indivíduos para chegar a certos modelos de sujeito que testemunham os tipos de relação com a norma mais frequentes numa sociedade. Vejamos o caso dos gerentes (setores médios) chilenos.

\subsection{Ideal}

Na gerência (setores médios) chilena se aprecia a enorme difusão e extensão no uso da noção de direito nos modos em que se constituem as expectativas sobre o social, mas também de si mesmo. Esta noção aparece como uma ferramenta a partir da qual os indivíduos codificam e produzem significações nos diferentes âmbitos da experiência social. Mesmo áreas que não estão submetidas à regulação pelos direitos positivos, como por exemplo as normas de cortesia, aparecem sendo concebidas como campos regulados pela lógica do direito. Desta maneira, os "direitos" percebidos e seu campo de ação excedem em muito o que é efetivamente coberto por eles em sua vertente positiva. Junto aos direitos trabalhistas está o direito de ser bem tratado, de que não se deve deixar o outro esperando, o direito de escutar o outro.

A quase totalidade dos intercâmbios e das relações com outros, é codificada fazendo uso desta noção, estabelecendo uma modalidade hegemônica e uníssona de apelar aos princípios plurais de justiça. Numa frase: o direito como Ideal tem um lugar definitivo nas expectativas sobre o funcionamento do social e uma função clara como orientação ideal nas configurações de sujeito. 


\subsection{As experiências sociais}

Não obstante, esta extensão e inscrição do ideal normativo, paradoxalmente acompanhada da leitura de sua experiência social como um campo de massiva vulnerabilidade deles mesmos e, mais especificamente, de uma vulneração normalizada. A experiência de vulnerabilidade aparece como parte consubstancial da paisagem social e da experiência cotidiana. A magnitude da percepção de vulnerabilidade, ou seja, de sua massividade e sua "normativididade" responde, pelo menos parcialmente, à contradição entre um robusto ideal normativo do qual fazem uso os sujeitos e uma realidade social que contradiz os princípios sobre os quais esta ordem deveria se fundar.

O que a experiência social mostra ao sujeito é que ela contém principalmente duas lógicas que põem em questão a ordem do direito e o que é reconhecido como seu fundamento por estes setores: o princípio da igualdade. Por um lado, a lógica do privilégio. Por outro, a lógica da confrontação de poderes.

A percepção da extensão de recursos de poder, que não correspondem ao marco de direito que se mobilizam e atualizam nos campos de relações que se supõem reguladas por este, apoia a deslegitimação de uma visão da vida social como uma ordem regida pelo ideal normativo. Se trata aqui, então, de um Ideal que ordena a leitura do social e que funciona, por um lado, como elemento estruturante da noção de sujeito mesma, porém, que no encontro com a amplidão das experiências sociais, o põem em questão, pois não alcança condições suficientes para orientar os atos e as interações. Sua falta de legitimidade e poder nas interações sociais concretas faz com que sejam outras as estratégias às quais os indivíduos recorrem. Mesmo quando se lê a situação em termos de direito ("está violando meu direito"), se atua sobre a base de lógicas efetivas distintas (se faz uso do tráfico de influências ou se produz uma posição de "submissão estratégica" às arbitrariedades do outro, por exemplo).

A experiência social, assim definida, conduz à intromissão da dinâmica vantagemdesvantagem. Ela revela a ameaça que se constitui para cada situação de se encontrar em desvantagem, ao mesmo tempo que é impregnada pelo sentimento de se encontrar em risco e de cair nesta situação. A experiência social mostra, deste modo, que a condição básica para se configurar e se submeter como sujeito é poder manejar ou se resguardar o 
melhor possível dos efeitos das lógicas de privilégio e de poder. O paradoxo está, portanto, no reconhecimento que, para se submeter como sujeitos ao social, resulta absolutamente necessário participar das lógicas sociais que eles mesmos denunciam como atentatórias, contra o que preservam, apesar de tudo, como ideal.

Como, então, neste contexto de relação entre Ideal (ideal normativo) e experiência social se constituem as possibilidades de configuração de sujeito?

\subsection{As configurações de sujeito}

Em função de sua constituição, vejamos as quatro principais configurações:

a) A primeira modalidade de configuração de sujeito é, como se pode supor, a figura do pragmático. O pragmático se orienta de maneira privilegiada a partir do que a experiência social lhe mostra como vias indicadas para habitar o social. Em ambos os casos, sua atuação está submetida às indicações provenientes da experiência social. Porém, esta configuração de sujeito pragmático se caracteriza pelo fato de que, devido à presença extensiva do Ideal, junto ao peso outorgado ao que a experiência social entrega em relação aos resquícios transitáveis a serem instrumentalizados e manejados, convive, portanto, com a crítica mais ácida à sociedade e ao seu funcionamento.

O pragmático denúncia e se articula numa lógica particular. Seus interesses próprios são reconhecidos como motor da ação, porém tematizados pela denúncia. Nessa modalidade, se trata de "fazer o que tem que ser feito", porém mobilizando ao mesmo tempo num discurso ideal e edificante de si mesmo. Se está obrigado a fazer o que se está fazendo, porque não há saída e se é parte da própria lógica de dominação do "sistema", do qual não é possível se afastar. Se "faz o que tem que ser feito", porém se testemunha, retoricamente, a insatisfação, a qual é retratada em termos de forçação de barra. Vejamos o exemplo no diálogo abaixo:

Homem 2: Se me recordo bem (...) numa reunião de gerentes (mandos médios) na famosa cidade empresarial de Huechuraba. Foram supervisores, diretores, gerentes, subgerentes, chefes. E os diretores (mandos superiores) relataram maravilhas da empresa, de sua segurança laboral, de tudo, tudo positivo, tudo muito bonito. Cada área, os chefes, os supervisores, os subgerentes, tinham falar sobre o mesmo em relação ao seu setor. Até que um supervisor pegou o microfone e começou a falar: "se de fato nós temos essas metas, temos todas essas coisas, ocorre que para alcançarmos esses objetivos e metas precisamos: 
ponto um, de capacitação, treinamento; ponto dois, de salários condizentes; ponto três, de...". Vocês sabem que, ao terminar, os diretores estavam assim se olhando uns aos outros, se olhavam assim como que ... Porém, quando aquele supervisor terminou de dissertar, todos, todos, todos nós paralisados nas cadeiras, começamos a aplaudir forte, a aplaudir muito, aplaudimos com a alma. Na semana seguinte, meu compadre, tchau.

Mulher 2: Eles não ganharam nenhum...

Mulher 1: Por ser justa...

Homem 2: E aí tinhas uma (...) força, ou seja, os subgerentes tinham de tudo, mas o que mais aplaudiram foram os chefes (mandos inferiores). Mas os subgerentes, os gerentes ...

Mulher 2: E espera aí, esse cara só pode estar querendo é procurar um novo emprego, se não já está (...)

A retórica argumentativa que desculpabiliza o sujeito e apoia a manutenção de uma imagem de si valorizada é um rendimento central que deve exercer o pragmático devido à vigência da função do Ideal. A desculpabilização se apoia no fato de que esta é a estratégia que é percebida como coletiva, ou mais bem, e de maneira mais precisa, forte, massiva. São, o que se pode chamar, a pesar do contrassenso à primeira vista, de pragmáticosidealistas. Ou seja, trágicos. Se inclina, diante da realidade, porém sem perder o horizonte do ideal desde o qual quiseram poder se sustentar. A configuração de pragmático-idealista é uma solução, resultado da força da experiência social que deve conviver com um ideal estendido e solidamente sustentado.

b) A segunda modalidade de configuração de sujeito é a que poderíamos chamar de sujeito crítico. Neste caso, o que aparece como predominante é o juízo crítico em relação à experiência social, em muitas ocasiões e com um alto nível de elaboração. Se denuncia profusamente a falta de funcionamento do ideal normativo. Se é capaz de expressar de maneira muito detalhada das formas consideradas negativas quando relacionadas à norma que aportam à erosão do ideal na sociedade. Se invoca o ideal de direito como orientador das relações e se tem plena consciência da própria condição de sujeito de direito como um elemento dorsal da leitura de si mesmo. A configuração de sujeito crítico é uma modalidade que se apresenta em duas versões. A primeira, está mais claramente vinculada à posição crítica orientada ao externo. A segunda, chamamos de versão autocrítica.

Na versão crítica se centram os elementos exógenos, a crítica e a denúncia se produz como uma rejeição ao que, na experiência social, se revela aos olhos, como causa 
da erosão do ideal normativo de direito. Mas, os modos de se referir são pouco discriminadores e mais próximo do que se identifica como causas ou responsabilidades em entes generalizados ou abstratos: "o sistema", "a justiça" ou os "poderosos". O ideal normativo aqui é fortemente sustentado em sua qualidade de aspiração e a experiência social claramente rejeitada. Porém, devido a esta tendência de colocar a experiência social como resultado de fatores externos de maneira tão acentuada, termina incidindo numa espécie de desresponsabilização.

Na versão autocrítica, o ideal normativo é marcadamente ativo. É uma aspiração e uma orientação efetiva para o sujeito. Não obstante, e isso é tão relevante que voltaremos ao tema a diante. Outros registros são invocados na leitura do que aporta a regulação das relaciones sociais - como a cordialidade, a empatia, a humanidade. Neste sentido, o ideal normativo de direito perde algo de seu carácter instrumental hermenêutico uníssono que o caracteriza nestes setores. Em todo caso, esta é uma versão que, à diferença notória da versão precedente, põe acento fortemente no ato individual. O sujeito que se configura, é aquele que questiona a própria participação na "desordem do mundo". Se encontra como efeito do anterior, como incorporação constante da responsabilidade própria e uma apelação ao peso correspondente à ação individual. Posto que a relação com a norma é percebida como um assunto individual, o campo privilegiado de construção da experiência social é a vida cotidiana. Neste sentido, se trata de uma modalidade de configuração de sujeito perfiladamente ética, na qual a vigilância dos próprios atos é continuada.

A configuração do sujeito-crítico é, assim, dual. O divisor de águas depende das causas da ação. No primeiro caso, o sujeito crítico exógeno é, e se contenta em ser, um comentador e um juiz certeiro do mundo. A lucidez crítica não se traduz em desejo de ação. O segundo, pelo contrário, o sujeito auto-crítico, é um ator lúcido do mundo. Dito em poucas palavras: no sujeito crítico exógeno a crítica sufoca a ação; no sujeito autocrítico, a consciência da urgência da ação individual prima sobre a crítica.

c) A terceira modalidade de configuração de sujeito é orientada pela amargura. 0 pivô aqui é a evidência da distância ao Ideal. A amargura sobrevém à medida em que se faz presente a constatação de que nem as "coisas" nem o próprio sujeito é o que poderia ou 
deveria chegar a ser. Se produz no interstício entre ideal e sua denegação pela experiência social. É a amargura que resulta da promessa não cumprida.

$\mathrm{Na}$ amargura, a raiva é, todavia, um pequeno motor, um fornecedor de algo relativo à ordem da paixão que evita a desesperança e a apatia. Na amargura resta, todavia, espaço para a denúncia do desencanto, para a figura, ainda que debilitada, do franco tirador. O pragmático, no fundo, e apesar da áurea trágica de quem se mostra (e quem sabe como fazer um show), foi acomodado com a ordem do mundo. Obtém vantagens dele, evita outras tantas desvantagens. O amargado, não pode ou não quer. A distância entre o Ideal e a experiência na qual se inscreve o pragmático, se transforma para ele num fosso sem salvação. Mas, para o pragmático-idealista, e diferente do que ocorre nos setores populares, essa distância é menos renúncia ao horizonte do direito como ideal regulatório das relações sociais.

O ponto mesmo de distância ao Ideal, funciona aqui, então, como a cena na que se fixa a atenção. Aqui, como em todas as modalidades de configuração de sujeito encontradas nesse setor, o Ideal se sustenta e a experiência social é considerada negativa, porém, diferente dos casos anteriores, neste, a experiência social se impõe em potência negativa, e, por mais que a sua potência corrosiva se mostre, o ideal se mantêm.

O amargado é prisioneiro de um dilema ao ponto que, constantemente, tem que se deslizar até as duas configurações precedentes. Ou se esforça em atribuir lhe um conteúdo mais coletivo para a sua frustração, transferindo ao "sistema" uma brecha não salvável que ele ressente entre o que seu Ideal Ihe dita e a experiência Ihe ensina, e se aproxima, por fim, do sujeito crítico exógeno. Ou se esforça em imitar o que fazem os outros, para aprender com eles, com o objetivo de escapar do que termina por se convencer que não é se não o fruto de um conjunto de incapacidades momentâneas e que deve, por fim, aprender a superar, de modo que se aproxima do sujeito pragmático.

O amargado se configura entre estes dois horizontes. Ele vive num país onde não se aplicam as normas, na medida em que o Ideal ditaria. Ele não pode fazer nada com isso, nem aproveitar os resquícios, nem exteriorizar, nem encontrar espaço para a agência. A amargura o invade, frente ao país ou frente a si mesmo. 
d) A quarta modalidade de configuração de sujeito é provavelmente a mais problemática. Por um lado, por seus efeitos no social, por outro, pela dificuldade para discernir e capturar analiticamente, no modo da primeira persona. Esta é uma modalidade extremadamente presente, mas, ao mesmo tempo, sempre colocada em terceira pessoa. O que caracteriza esta modalidade é que, em nome da lei ou do direito, o que o sujeito encarna é o excesso.

Essa modalidade de sujeito do excesso, um excesso que se materializa com abuso, é uma modalidade na qual se deteriora o ideal normativo amparado nas atribuições da autoridade, bem como, nas poucas ocasiões, em nome do resguardo do próprio Ideal. Está fortemente vinculada às instituições, às funções: à ideia de um coletivo, ainda que se encarne em alguém singular. É neste sentido que esta modalidade pode se conter na afirmação: "a lei somos nós". Se trata de nós, do coletivo, ao que se representa - nós os médicos, nós os ricos, nós os pais de família, nós policiais, e uma lista extensa de outros nós-, e que legitima encarnar a lei ou a norma que, ao final de contas, se corrói.

Vale a pena reiterar que, no caso dos gerentes (setores médios) chilenos, o sujeito do excesso, aquele que corrói a norma, o faz em nome da própria ordem normativa. Aparece como um excesso normativo. O recurso ao Ideal aqui se mantém: se parte recorrendo a ele desde uma posição de legitimidade, institucional ou social, e se faz uso desta legitimidade e em nome dela, e por conta do excesso, se transgride a norma. Se trata do uso desmedido da posição de vantagem. É a traição ao Ideal que se transveste de fidelidade a ele mesmo.

Esta posição orientada pelo excesso da norma, se revela nas atuações daqueles que se sentem em posição de exigir porque pagam:

no colégio não há respeito pelos professores, nós professores somos apenas empregados, somos praticamente babás, pais porque eles estão te pagando, eles são os donos de te dar um par de rabiscos (Mulher, mestiça, adulta).

Também aparece nos atropelos das forças policiais, como no caso de um jovem detido por consumo de álcool sem ter consumido. Há uma constelação na qual o que se põe em jogo e se castiga é propriamente o não ter se comportado com a devida submissão à autoridade. Para dar só dois exemplos. 
Em todos estes casos, as normas se põem ao serviço dos próprios interesses ou benefícios. O excesso é a sustentação mesma do sujeito. O risco: que num contexto marcado pela confrontação de poderes e da mobilidade dos lugares ocupados na dinâmica vantagemdesvantagem, esta é uma posição sempre provisória. A exigência: ela só sobrevive na condição de o sucesso dá uma salvaguarda com o ideal normativo que lhe dá legitimidade: tal é a força da ação do Ideal normativo nesses setores.

As quatro modalidades são, por certo, modelos presentes na sociedade chilena. Não correspondem a perfis psicológicos individuais: se trata de modos sociais de configurações de sujeito que dão conta da orientação e legitimação da ação num determinado contexto histórico. Nesse sentido, os indivíduos encarnados podem mostrar uma maior impregnação a um modelo ou a outro, porém também, podem, em certas ocasiões, transitar entre configurações segunda a conjuntura ou inclusive o momento de vida.

\section{CONCLUSÃO}

Como mostra o até aqui desenvolvido, apesar de as experiências sociais e a inscrição do Ideal poderem ter características compartilhadas para um mesmo sector social (ou para um gênero ou uma geração), eles não se remetem de maneira mecânica à mesma relação com as normas. É uma certa articulação deles que constituirá a estrutura das várias configurações de possíveis sujeitos em uma dada sociedade. Embora as experiências sejam parecidas e os ideais inscritos do mesmo teor existam sempre o espaço da liberdade, este é o requisito ético, aberto a cada um para definir suas relações com o mundo, com os outros e consigo mesmo.

Dizer que os setores médios chilenos são transgressores seria tão falso como sustentar o contrário, e, em todo caso, não nos leva muito longe. O importante é destacar como na sociedade o principal desafio a ser enfrentado é a relação entre um ideal de presença em desdobramento e uma realidade social que é constantemente responsável por negá-lo.

É neste interregno que o trabalho moral ordinário do sujeito, como chegamos a vêlo, é capaz de explicar as variantes na relação que os indivíduos estabelecem com as 
normas da mesma sociedade sem, ao mesmo tempo, pluralizar a análise indefinidamente ao reduzi-lo a variantes psicológicas individuais.

\section{REFERÊNCIAS}

ARAUJO, Kathya. Dignos de su arte. Sujeito y lazo social en el Perú de las primeras décadas del siglo XX. Madrid/Frankfurt: Iberoamericana Vervuert Verlag, 2009a.

ARAUJO, Kathya. Habitar lo social. Usos y abusos en la vida cotidiana en el Chile actual. Santiago: LOM, 2009b.

BELLAH, R. et al. Habits of the Heart. Berkeley: University of California Press, 1985.

DA MATTA, Roberto. Carnavales, malandros y héroes. Hacia una sociología del dilema brasileño. México: Fondo de Cultura Económica, 1978.

DE SOTO, Hernando. El Otro sendero. Lima: Editorial El Barranco, 1986.

FOUCAULT, Michel. La arqueología del saber. México: Siglo XXI, 1990.

FOUCAULT, Michel. Las palabras y las cosas. Una arqueología de las ciencias humanas. Madrid: Siglo XXI, 1998.

GARRETÓN, Manuel A. La sociedad en que vivi(re)mos. Santiago de Chile: LOM Ediciones, 2000.

JOCELYN-HOLT, A. El peso de la noche: nuestra frágil fortaleza histórica. Santiago: Planeta, 1999.

LARRAÍN, Juan. Identidad Chilena. Santiago: LOM Ediciones, 2001.

LECHNER, Norbert. Las sombras del mañana. La dimensión subjetiva de la política. Santiago: LOM Ediciones, 2002.

MARTUCCELLI, Danilo. ¿Existen Indivíduos en el Sur? Santiago: LOM, 2010.

MÉNDEZ, Juan; O’DONNELL, Guillermo; PINHEIRO, Paulo Sérgio (Coord.). La (in)efectividad de la ley y la exclusión en América Latina. Buenos Aires: Paidós, 2002.

NINO, Carlos. Un país al margen de la ley. Buenos Aires: Emecé, 2005.

NISBET, R. A. The Sociological Tradition. London: Heinemann Educational Books, 1973 [1966].

NUGENT, G. El poder delgado. Lima: Friedrich Ebert Stigftung, 1996

NUGENT, G. Composición sin título. Lima: Friedrich Ebert Stigftung, 1998.

NUGENT, G. Clase media: de la mano invisible a la clase invisible. In: GAMERO, J.; Zeballos, M. (Eds.). La clase media ¿existe?. Lima: Desco, 2003. p. 15-46. 
O'DONNELL, Guillermo. ¿Y a mi qué me importa? Notas sobre sociabilidad y política en Argentina y Brasil, Buenos Aires: CEDES, 1984.

PNUD. Programa de las naciones unidas para el desarrollo, PNUD. Informe Desarrollo Humano en Chile. Las paradojas de la modernización. Santiago: PNUD, 1998.

THOME, H. Das Konzept sozialer Anomie als Analyseinstrument. In: Waldmann, Peter (Hg.). Diktatur, Demokratisierung und soziale Anomie. Schriften der Philosophischen Fakultäten der Universität Augsburg Nr. 70. München: Verlag Ernst Vögel., 2003. p. 37-59

SCHWARTZMAN, S. Coesão social, democracia e corrupção. São Paulo: IFHC, 2007.

SHEPARD, B. El Doble Discurso sobre los Direitos Sexuales y Reproductivos en América Latina: el Abismo entre las Políticas Públicas y los Atos Privados". Revista Conciencia Latinoamericana, Córdoba, n. 3 - Católicas por el Direito a Decidir, 2000.

SMULOVITZ, C.; URRIBARRI, D. Poderes judiciales en América latina: entre la administración de aspiraciones y la administración del direito. São Paulo: IFHC, 2007.

ZIZEK, Slavoj. El sublime objeto de la ideología. México: Siglo XXI, 1992.

ZIZEK, Slavoj. El espinoso sujeito. Buenos Aires: Paidós, 2001.

ARAUJO, Kathya. A relação com as normas na América

Latina e o ordinário trabalho moral do sujeito. RBSD -

Revista Brasileira de Sociologia do Direito, v. 5, n. 3, p. 14-

37, set./dez. 2018. 